\title{
STUDY THE ACTIVITY OF TITANIUM DIOXIDE NANOPARTICLE USING ORANGE G DYE
}

\author{
Hazim Y. Algubury \\ Babylon University, College of Science for women, Chemistry Department \\ E-mail : h.yahya40@yahoo.com \\ Received: 25 May 2016 Revised: 22 July $2016 \quad$ Accepted : $1^{\text {st }}$ Aug 2016
}

\begin{abstract}
In this article photocatalytic degradation of orange $G$ dye was carried out using titanium dioxide nanoparticles under UV irradiation. The amount of photocatalyst, concentration of orange $\mathrm{G}$ dye, effect of light intensity and effect of PH were studied as variables. The highest photocatalytic degradation of orange $\mathrm{G}$ dye was observed at $0.14 \mathrm{gm} / 100 \mathrm{~cm}^{3}$ of titanium dioxide nanoparticles and $15 \mathrm{ppm}$ of dye. Orange $\mathrm{G}$ dye photocatalytic degradation was favorable in the PH 6.4 and $8.22 \mathrm{~mW} / \mathrm{cm}^{2}$ light intensity. Photocatalytic degradation of orange G dye follow the first order of reaction .photocatalytic degradation of orange $G$ dye has been studied using different concentrations of titanium dioxide nanoparticles suspended in an aqueous solution of orange $\mathrm{G}$ dye irradiated by 125 watts ultraviolet radiation in a vessel reactor at room temperature, with $10 \mathrm{~cm} / \mathrm{min}$ air bubble has been passed through the solution .Photocatalytic degradation of orange $\mathrm{G}$ dye presence of light and catalyst is essential for the degradation. Increasing dye concentration resulted in decreased photocatalytic degradation efficiency. The percentage efficiency of degradation reactive blue equals $93.98 \%$.The activation energy has been calculated it was found equal to $\quad 22.29 \pm 1 \mathrm{~kJ} \cdot \mathrm{mol}^{-1}$. All experiments are determined using UV-visible spectrophotometer analyser.
\end{abstract}

KEYWORDS: Photodegradation, Nanoparticle, Orange G, Titanium dioxide.

\section{INTRODUCTION}

In the recent years, the focus has been shifted to photocatalysis degradation of synthesized dyes and other organic pollutants. Titanium dioxide is widely applied for photocatalytic degradation of organic and inorganic pollutants ( Rosana et al., 2000; Mukhlish et al., 2013).

Prepared fly ash-Titanium dioxide nanocomposite has been applied for treatment multi-pollutants wastewater (multi-pollutant synthetic wastewaters loaded with copper cations and two industrial dyes: the acid dye Bemacid Blau and the reactive dye Bemacid Rot ) (Maria et.al.,2015). Modified fly ash (FA) mixed with $\mathrm{TiO}_{2}$ photocatalyst has been employed to removal different pollutants such as dyes and heavy metals using photo-Fenton systems ((Maria et.al.,2013) . Nanocrystalline $\mathrm{TiO}_{2}$ were synthesized by the sol-gel method has been employed for photocatalytic degradation of some dyes such as methylene blue and Congo red (Mukhlish et.al. 2013). Fujishima and Honda (1972) have been proved that water could be split into hydrogen and oxygen, by using $\mathrm{TiO}_{2}$ and ultraviolet radiation (Fujishima et al.1972).

In the last decay, Titanium dioxide and other semiconductors( $\mathrm{ZnO}, \mathrm{CdS}, .$. etc) has been widely applied for photocatalytic degradation of a wide range of pollutants such as an organic dye, pesticides and water purification (Yadollah et al.2011).

Basically the environmental pollution has been treated using conventional method include chemical, physical and biological processes, this processes are not always succeeded for treating pollutants, recently the advanced oxidation process (AOP) has been applied for dye removal and many other organics treated (Cheng et al., 2016; Abouzlam et al., 2015), in which method the hydroxyl radical firstly generated to mineralized organic materials. When the titanium dioxide nanoparticle has been 
irradiated with energy equal or greater than the band gap of semiconductor the electrons moved toward the conduction band of semiconductor leaving a positive hole in the valence band (Suzuki et al., 2015; Jeirani et al., 2015; Aline et al.2016). The electrons in the conduction band inter photoreduction process with particles adsorbed on the

$$
\begin{aligned}
& \mathrm{TiO}_{2}+\mathrm{hv} \longrightarrow \mathrm{TiO}_{2}\left(\mathbf{e}_{\mathrm{CB}}^{-}+\mathrm{h}_{\mathrm{VB}}{ }^{+}\right) \\
& \mathrm{TiO}_{2}\left(\mathrm{~h}_{\mathrm{VB}}{ }^{+}\right)+\mathrm{H}_{2} \mathrm{O} \longrightarrow \mathrm{TiO}_{2}+\mathrm{H}^{+}+\mathrm{OH}^{\cdot} \\
& \mathrm{TiO}_{2}\left(\mathrm{~h}_{\mathrm{VB}}{ }^{+}\right)+\mathrm{OH} \longrightarrow \mathrm{TiO}_{2+} \mathrm{OH}^{\cdot} \\
& \mathrm{TiO}_{2}\left(\mathrm{e}_{\mathrm{CB}}^{-}\right)+\mathrm{O}_{2} \longrightarrow \mathrm{TiO}_{2}+\mathrm{O}_{2}^{-} \\
& \mathrm{O}_{2}^{-\cdot}+\mathrm{H}^{+} \longrightarrow \mathrm{HO}_{2} \text {. } \\
& \text { Dye }+\mathrm{OH}^{\prime} \longrightarrow \text { Degradation products } \\
& \text { Dye }+\mathbf{h}_{\mathrm{VB}}{ }^{+} \longrightarrow \text { Oxidation products } \\
& \text { Dye }+\mathbf{e}_{\mathrm{C} \overline{\mathrm{B}}} \longrightarrow \text { Reduction products }
\end{aligned}
$$

In this work orange $\mathrm{G}$ dye $\left(\mathrm{C}_{16} \mathrm{H}_{10} \mathrm{~N}_{2} \mathrm{Na}_{2} \mathrm{O}_{7} \mathrm{~S}_{2}\right)$ has been used to investigate the photoactivity of titanium dioxide nanoparticle metal oxide. Orange $G$ dye is an anionic mono azo dye because it contains negatively charged sulphonate groups, bright orange, soluble in water slightly soluble in ethanol. Azo dyes are chemical stability and versatility; however, most of them are non-biodegradable, toxic. Orange $G$ dye has been used in the colouring of synthetic wool, silk materials and leather industry (Yang et al., 2006; Lachhe et al., 2002). surface of titanium dioxide nanoparticle, and the positive hole in the valance band react with adsorbed pollutant on the surface of the semiconductor. The suggested mechanism for degradation the orange $\mathrm{G}$ dye has been proposed as shown in the equations below (Akpan et. al., 2009):

\section{MATERIALS \& METHODS}

The chemicals used in this work are listed below and all chemicals are standard without further purification.

1-Titanium dioxide nanoparticle $\left(\mathrm{TiO}_{2}\right)$ : Supplied by Fluka AG.

2 - Orange $\mathrm{G}$ dye : supplied by sigma Aldrich .

3- Sodium hydroxide ( $\mathrm{NaOH}$ ): Supplied by Fluka AG.

4-Hydrochloric acid ( $\mathrm{HCl}$ ): Supplied by Fluka AG.

Experiments were carried out in glass photochemical reactor. The cylindrical annular - type reactor consisted of two parts. 
The first part was an outside thimble; running water was passed through the thimble to cool the reaction solution. Owing to the continued cooling, the temperature of the reaction solution was maintained at room temperature. The second part was an inside thimble and the reaction solution $\left(100 \mathrm{~cm}^{3}\right)$ was put in the reaction chamber.

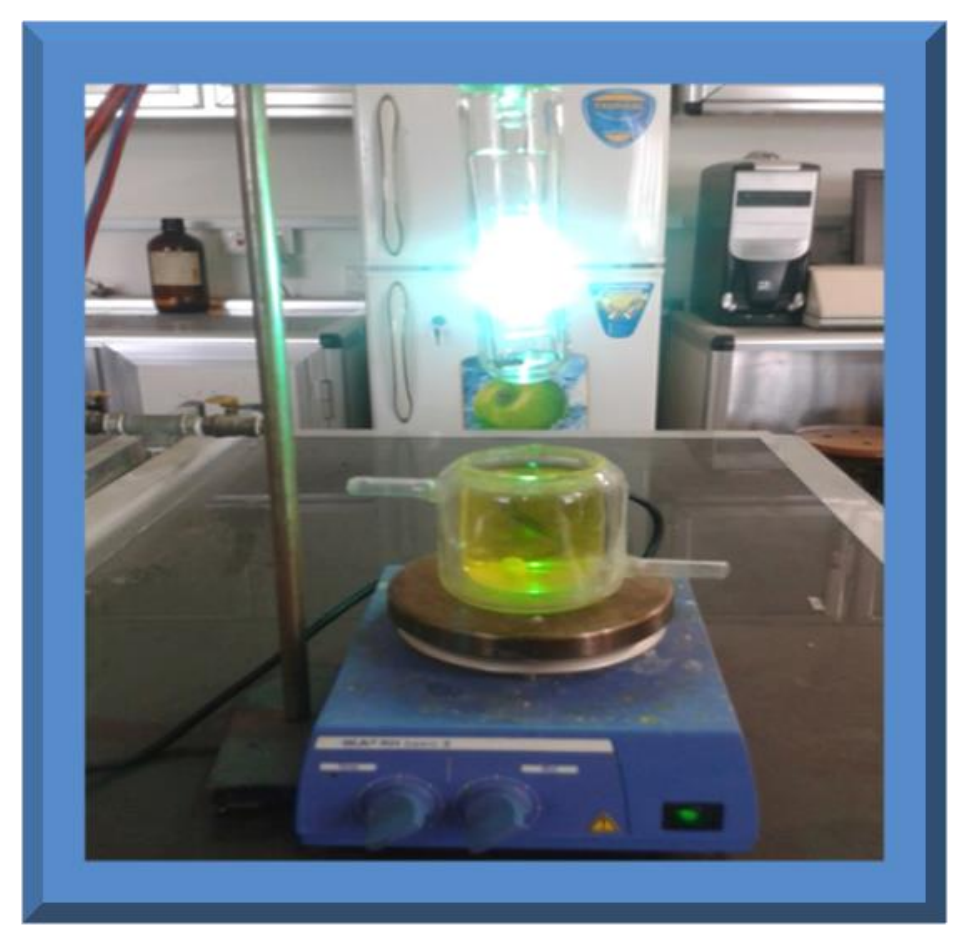

Figure 1- Main parts of the photocatalytic cell used in Photocatalytic degradation of orange G dye.

\section{RESULTS AND DISCUSSION}

\section{1 - The Effect of dosage masses of Titanium dioxide nanoparticle on photocatalytic degradation of orange $\mathbf{G}$ dye:}

A series of experiments has been performed by varying the amount dosage mass of titanium dioxide nanoparticle range $\left(0.04-0.35 \mathrm{gm} / 100 \mathrm{~cm}^{3}\right)$, in order to obtain highest degradation efficiency of orange $\mathrm{G}$ dye. The optimum conditions in which all experiments carried out $15 \mathrm{ppm}$ orange $\mathrm{G}$ dye, $\mathrm{PH}=6.4,10 \mathrm{~cm}^{3} / \mathrm{min}$ flow rate of an air bubble, at room temperature $298 \mathrm{~K}$
- As shown in Figure 2 photocatalytic degradation of orange $\mathrm{G}$ dye increases with gradually increases the mass of titanium dioxide nanoparticle. The maximum percentage of photodegradation was obtained at $0.14 \mathrm{gm} / 100 \mathrm{~cm}^{3}$ of titanium dioxide nanoparticle, which can provide the highest absorption of light. Furthermore, increase the number of active sites with increasing the masses of titanium dioxide nanoparticle leads to enhanced the number of adsorbed orange $\mathrm{G}$ dye molecules, consequently increase the percentage of photodegradation of dye. When the amount of loading mass of titanium dioxide nanoparticle was increased beyond 
$0.14 \mathrm{gm} / 100 \mathrm{~cm}^{3}$, the percentage degradation decreased. This can be attributed to the light absorption will be limited only to the first layers of orange $\mathrm{G}$ dye, Moreover the turbidity of the solution has been increased therefore reduces the light penetration through the solution known as light screening effect . Furthermore, light scattering at high dosage mass of titanium dioxide nanoparticle In such condition, a part of the titanium dioxide nanoparticle surface area probably decrease and becomes unavailable for photon absorption and orange $\mathrm{G}$ dye adsorption, thus reduces the photocatalytic reaction.(Rachita et al., 2012; Hazim, 2016). 


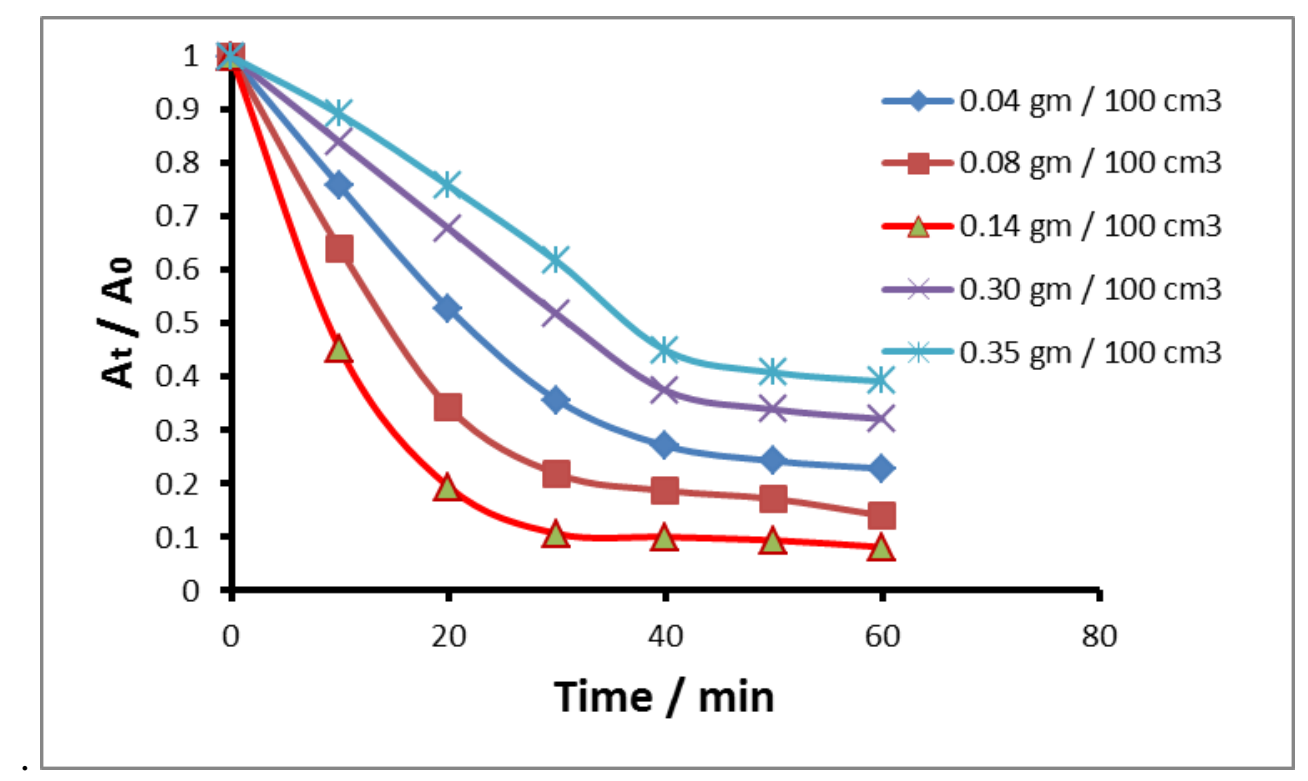

Figure 2- Effect of photocatalyst loading on photodegradation of orange G dye using UV radiation, initial condition: $15 \mathrm{ppm}$ orange $\mathrm{G}$ dye and $\mathrm{pH}=6.4$.

\section{2- The Effect of initial concentration of orange $G$ dye on photocatalytic degradation processes:}

A series of experiments were carried out for investigated the effect of initial concentration range $(15-40 \mathrm{ppm})$ on photocatalytic degradation process of orange $\mathrm{G}$ dye, using $0.14 \mathrm{gm} / 100 \mathrm{~cm}^{3}$ of titanium dioxide nanoparticle , $\mathrm{PH}=6.4$, irradiated with $8.22 \mathrm{~mW} / \mathrm{cm}^{2}$ ultraviolet ,flow rate of air bubble $10 \mathrm{~cm}^{3} / \mathrm{min}$, at room temperature. The results are listed in figure 3 . It has been observed that the rate of photocatalytic degradation gradually decreases with the increasing of initial orange $\mathrm{G}$ dye concentration. This behavior could be explained: the concentration 15 ppm was the optimum concentration to cover the largest area of the titanium dioxide nanoparticle particles, therefore absorbed maximum exciting photons to generate higher concentration of the activated titanium dioxide nanoparticle semiconductor. At a high orange $G$ dye concentration beyond $15 \mathrm{ppm}$, the presumption is that the active sites are covered by orange $G$ dye that can cause reduced generation of an electron-hole pair, which subsequently reduces the photodegradation efficiency. Another reason which may be responsible for the reduction in photocatalytic degradation efficiency is the excess of orange $G$ dye prevents the penetration of light through the successive layers of orange $\mathrm{G}$ dye, on the titanium dioxide nanoparticle surface. (Peidong et al., 2016; Jianguo et al., 2016; Hazim et.al. 2016). 


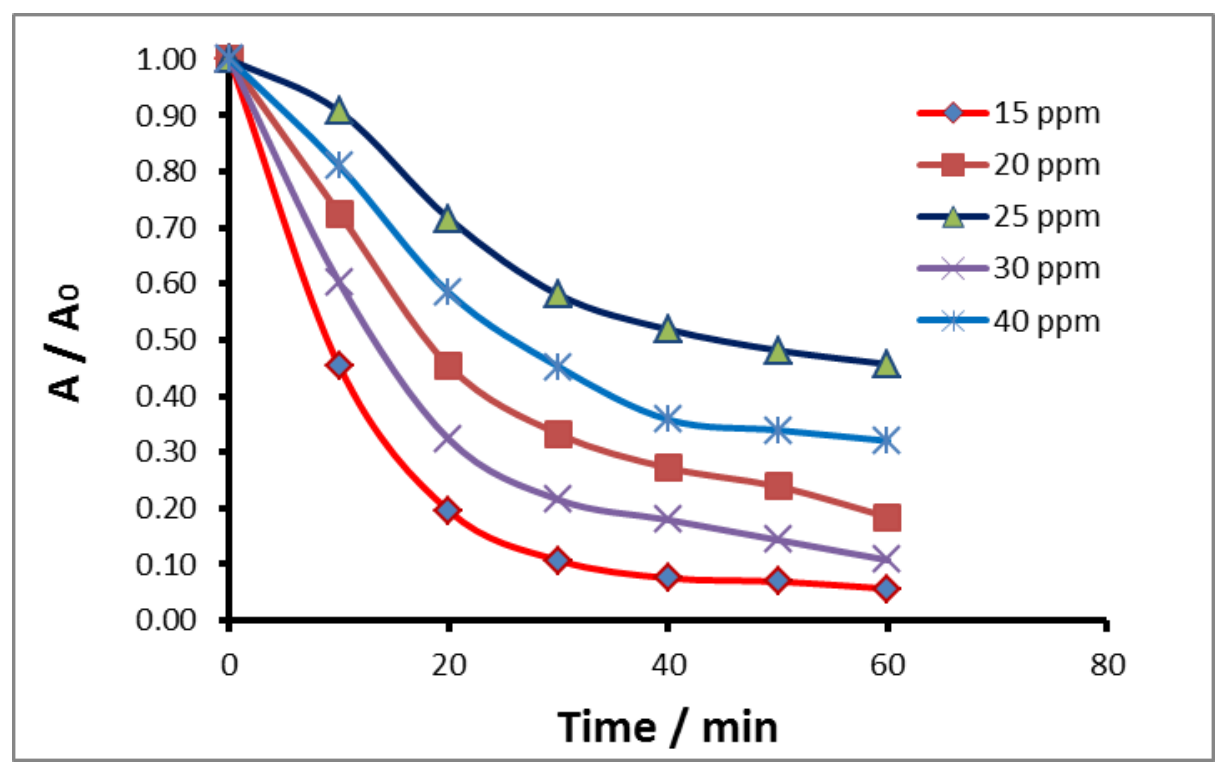

Figure 3- Effect of orange $\mathrm{G}$ dye concentration on photocatalytic degradation under UV irradiation, initial condition: amount of titanium dioxide nanoparticles $=0.14 \mathrm{gm} / 100 \mathrm{~cm}^{3}$ and $\mathrm{pH}=6.4$.

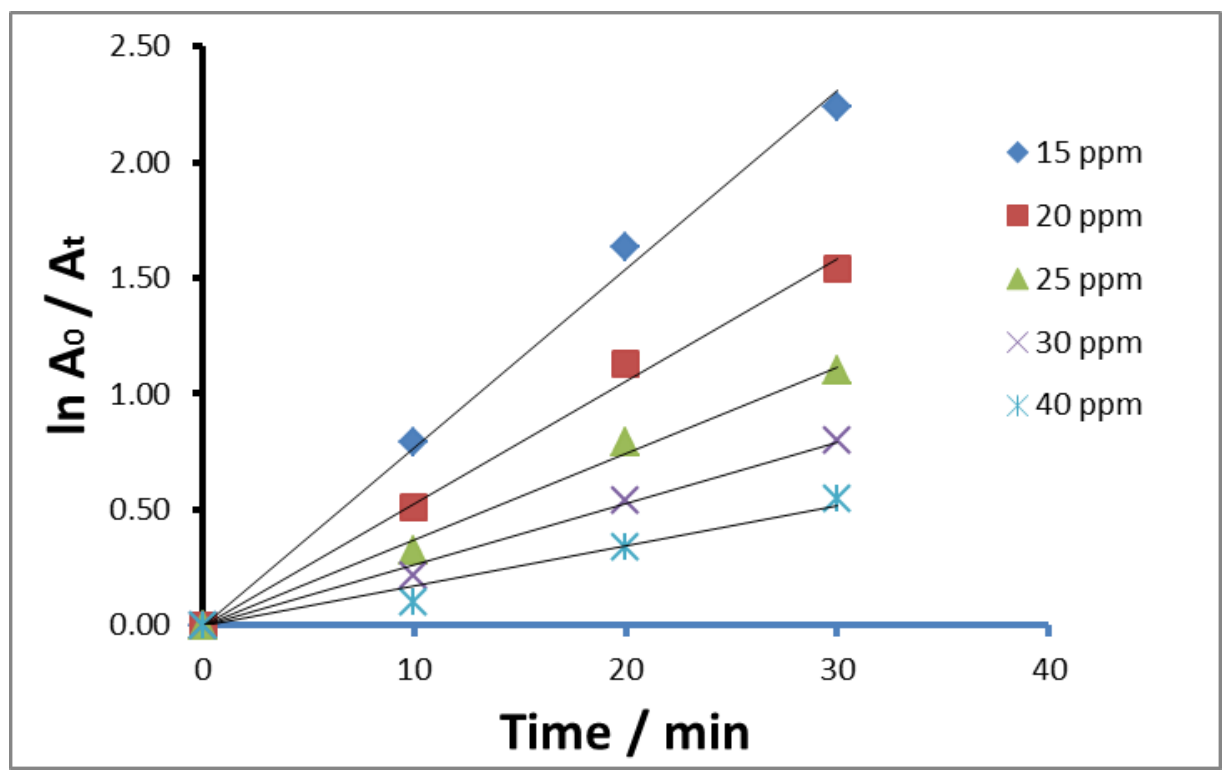

Figure 4 - Kinetics studies of the photocatalytic degradation of orange $\mathrm{G}$ dye under UV irradiation, amount of titanium dioxide nanoparticles $=0.14 \mathrm{gm} / 100 \mathrm{~cm}^{3}$ and $\mathrm{pH}=6.4$. 
The present experiment has been performed for investigated the order of reaction under optimized condition, $0.14 \mathrm{gm}$ / $100 \mathrm{~cm}^{3}$ of titanium dioxide nanoparticles ,8.22 $\mathrm{mW} / \mathrm{cm}^{2}, \mathrm{PH}=6.4$. Plotting $\ln \mathrm{A}_{0} / \mathrm{A}_{\mathrm{t}}$ versus Time give straight line as shown in figure 4 ,these results show that the photocatalytic degradation of orange $G$ dye follows the first order reaction (Da-Rui et.al., 2011 ) .

\section{3- Effect of PH parameter on photocatalytic degradation of orange $G$ dye:}

In this parameter, It has been interested to investigate the charge between the semiconductor surface and orange $\mathrm{G}$ dye at $\mathrm{PH}$ range ( 2 - 10 ), The $\mathrm{pH}$ of the aqueous

$$
\begin{gathered}
\text { Ti-OH }+\mathbf{H}^{+} \rightarrow \text { TiOH}_{2}^{+} \quad \text { acidic medium } \\
\text { Ti-OH }+\mathbf{O H}^{-} \rightarrow \mathbf{T i O}^{-}+\mathbf{H}_{2} \mathbf{O} \quad \text { alkaline medium }
\end{gathered}
$$

Figure 5 shown that the photodegradation efficiency of orange $\mathrm{G}$ dye increased with increasing $\mathrm{pH}$ until reach $\mathrm{PH}=6.4$ (the zero point charge of titanium dioxide $=6.3$ ) (Herrmann et al., 1993; Evgenidou et al., 2005) in which photocatalytic efficiency equal $93.71 \%$ due to produce the hydroxyl radical which is generated from oxidizing hydroxyl ions, on the other hand increases solution was adjusted using $0.01 \mathrm{~N} \mathrm{HCl}$ and $0.01 \mathrm{~N} \mathrm{NaOH}$. A series of experiments has been performed under the optimum condition , $0.14 \mathrm{gm} / 100 \mathrm{~cm}^{3}$ of the loaded mass of titanium dioxide nanoparticles, the 15 ppm concentration of orange $G$ dye , 10 $\mathrm{cm}^{3} / \mathrm{min}$ flow rate if air bubble,irradiated with $8.22 \mathrm{~mW} / \mathrm{cm}^{2}$, and room temperature. Basically, this factor includes two steps starting with hydroxylated the surface of titanium dioxide nanoparticles ( $\mathrm{Ti}-\mathrm{OH})$ in aqueous solution. The second step reacting the hydroxide surface ( $\mathrm{Ti}-\mathrm{OH})$ with acidic medium (low $\mathrm{PH}$ ) absorb protons to become positively charged and with an alkaline medium (high $\mathrm{PH}$ ) lose protons to become negatively charged as shown in equation below (Yadolla et al., 2012):

absorption of orange $\mathrm{G}$ dye on the surface of titanium dioxide nanoparticles. Above the zero point charge of titanium dioxide nanoparticles in alkaline medium, photocatalytic degradation of orange $G$ dye has been gradually decreasing due to reducing the orange $\mathrm{G}$ dye absorbed on the negative charge surface of titanium dioxide Nanoparticles. 


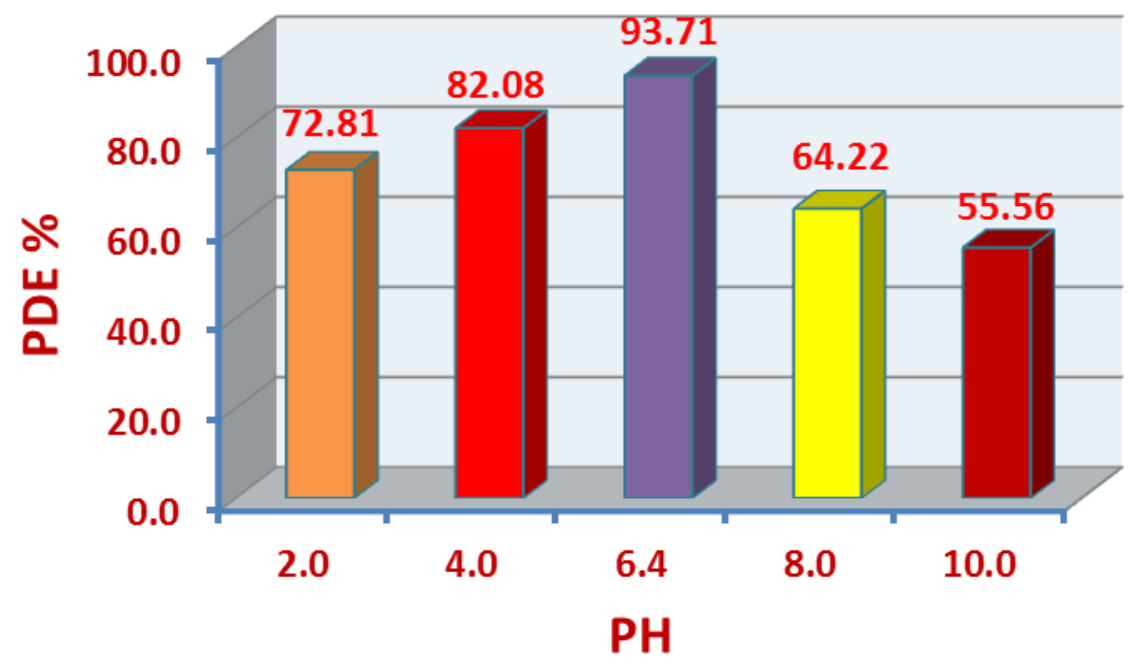

Figure 5 - Photocatalytic degradation of orange $\mathrm{G}$ dye at variation initial $\mathrm{pH}$ using UV radiation, initial orange $\mathrm{G}$ dye concentrations $=15 \mathrm{ppm}$, amount of photocatalyst titanium dioxide nanoparticles $=0.14 \mathrm{gm} / 100 \mathrm{~cm}^{3}$

\section{4- The effect of light intensity on photo degradation of orange $G$ dye using titanium dioxide nanoparticle.}

Several experiments were carried out for studied the effect of light intensity on photocatalytic degradation of orange $\mathrm{G}$ dye in the range $(2.15-8.22) \mathrm{mW} / \mathrm{cm}^{2}$. The rate of photodegradation of orange $\mathrm{G}$ dye, was measured at fixed mass of titanium dioxide nanoparticle $\left(0.14 \mathrm{gm} / 100 \mathrm{~cm}^{3}\right)$ with $15 \mathrm{ppm}$ of orange $\mathrm{G}$ dye, $\mathrm{PH}=6.4,10 \mathrm{~cm}^{3} / \mathrm{min}$ flow rate of an air bubble at room temperature. It has been observed that on increasing the light intensity as in Figure 6, the percentage degradation of orange $\mathrm{G}$ dye increased. This may be attributed to the increased electronhole formation which was required for the electron transfer from the valence band to the conduction band of titanium dioxide nanoparticle and, hence electron-hole recombination is negligible (Wen et al., 2006; Hazim et al., 2015; Hazim et al., 2015). The light intensity $8.22 \mathrm{~mW} / \mathrm{cm}^{2}$ give the optimum photodegradation efficiency which is equal to $93.98 \%$. The results of the change in photocatalytic degradation efficiency (P.D.E) with light intensity plotted in Figure 7. 


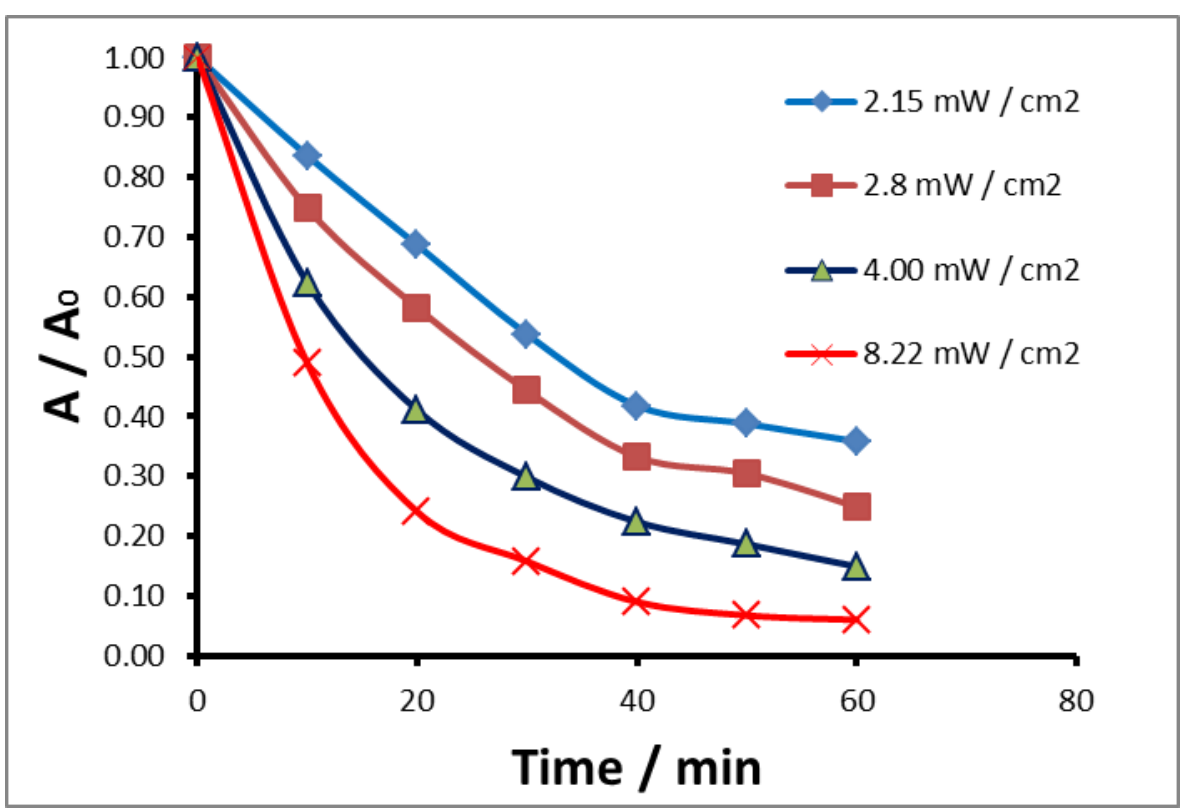

Figure 6 -The change of $\left(A_{t} / A_{0}\right)$ with irradiation time at the different light intensity with $0.14 \mathrm{gm} / 100 \mathrm{~cm}^{3}$ of titanium dioxide nanoparticle, $\mathrm{PH}=6.4$, on photocatalytic degradation of orange $\mathrm{G}$ dye . 


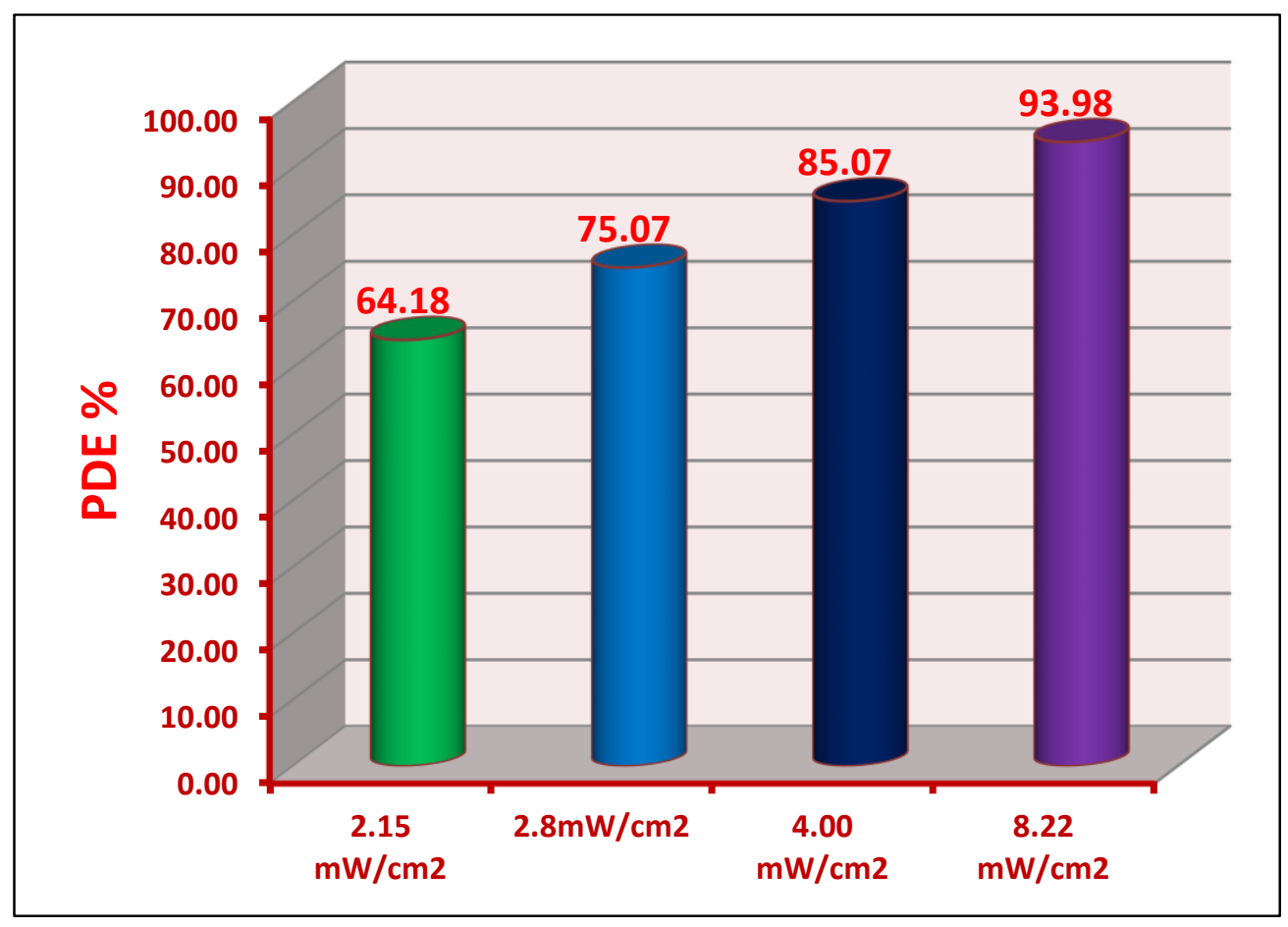

Figure 7-The change of Photocatalytic Degradation Efficiency with irradiation time at different light intensity, initial orange $\mathrm{G}$ dye concentrations $=15 \mathrm{ppm}$, the amount of photocatalyst titanium dioxide nanoparticles $=0.14 \mathrm{gm} / 100 \mathrm{~cm}^{3}$, and $\mathrm{PH}=6.4$.

\section{5- Effect of temperature on photocatalytic degradation of orange G dye:}

A series of experiments has been performed for studying photocatalytic degradation of orange dye at various temperatures in the range $(283-303 \mathrm{k})$, at $0.14 \mathrm{gm} / 100 \mathrm{~cm}^{3}$ loaded mass of titanium dioxide nanoparticles, $15 \mathrm{ppm}$ concentration of orange $\mathrm{G}$ dye $, \mathrm{PH}=6.4,10 \mathrm{~cm}^{3} / \mathrm{min}$ flow rate of an air bubble,irradiated with $8.22 \mathrm{~mW} / \mathrm{cm}^{2}$.

It has been observed that on increasing the temperature as shows in Figure 8, the percentage degradation of orange $\mathrm{G}$ dye increased This may be attributed to the increased of hydroxyl radical generation, and electron-hole recombination is negligible, therefor as consequence photocatalytic degradation of orange $G$ dye has been an enhancement. Figure 10. Represent Arrhenius relationship to calculate the activation energy of the reaction from the slope of the graph when plot rate constant ( $\mathrm{k}$ ) against $(1 / \mathrm{T})$, the rate constant was calculated from the first order of reaction equation as shown in figure 9 . The activation energy was found equal to $22.29 \pm 1 \mathrm{~kJ} \mathrm{~mol}^{-1}$ (Shaobin et al., 2005; Ruwaida et.al, 2016). 


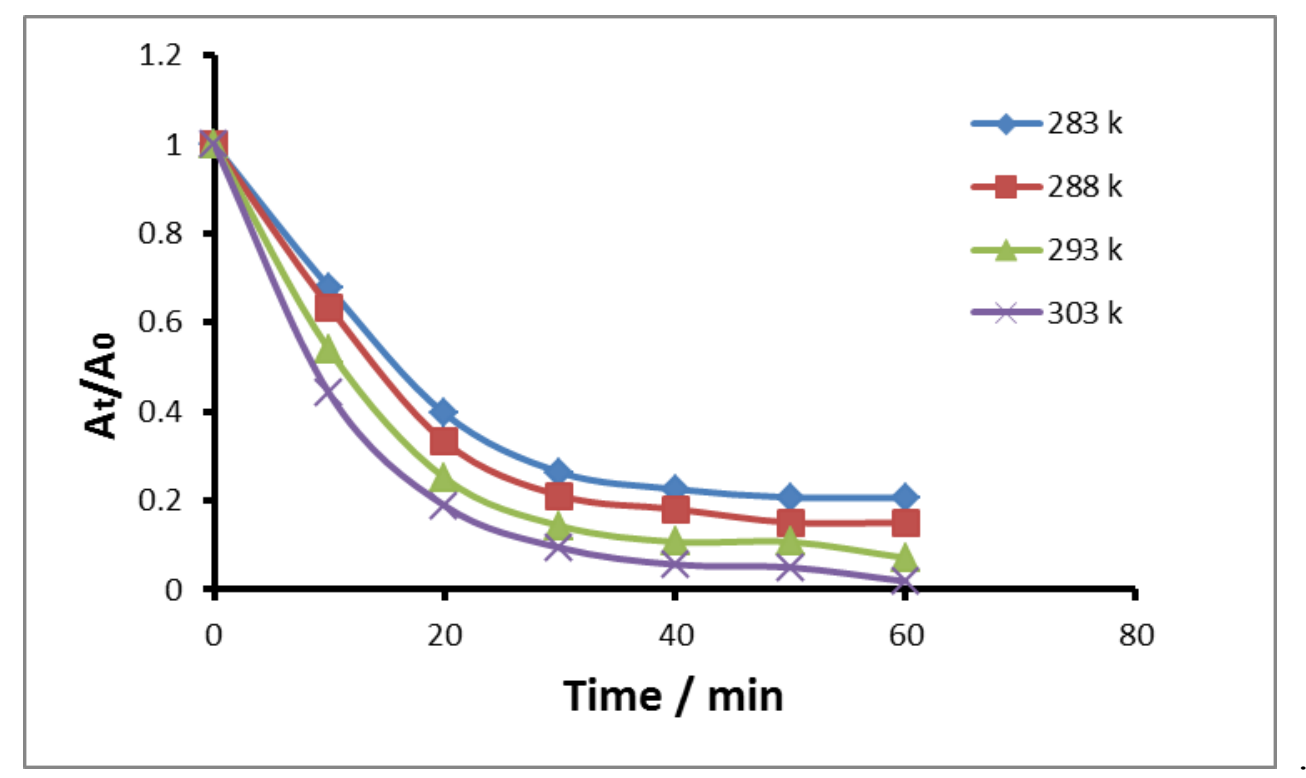

Figure 8- Effect of temperature on the degradation of orange $\mathrm{G}$ dye by photocatalytic degradation process. Experimental conditions: $0.14 \mathrm{gm} / 100 \mathrm{~cm}^{3}$ titanium dioxide nanoparticles, $15 \mathrm{ppm}$ initial concentration of orange $\mathrm{G}$ dye, $\mathrm{pH} 6.4$.

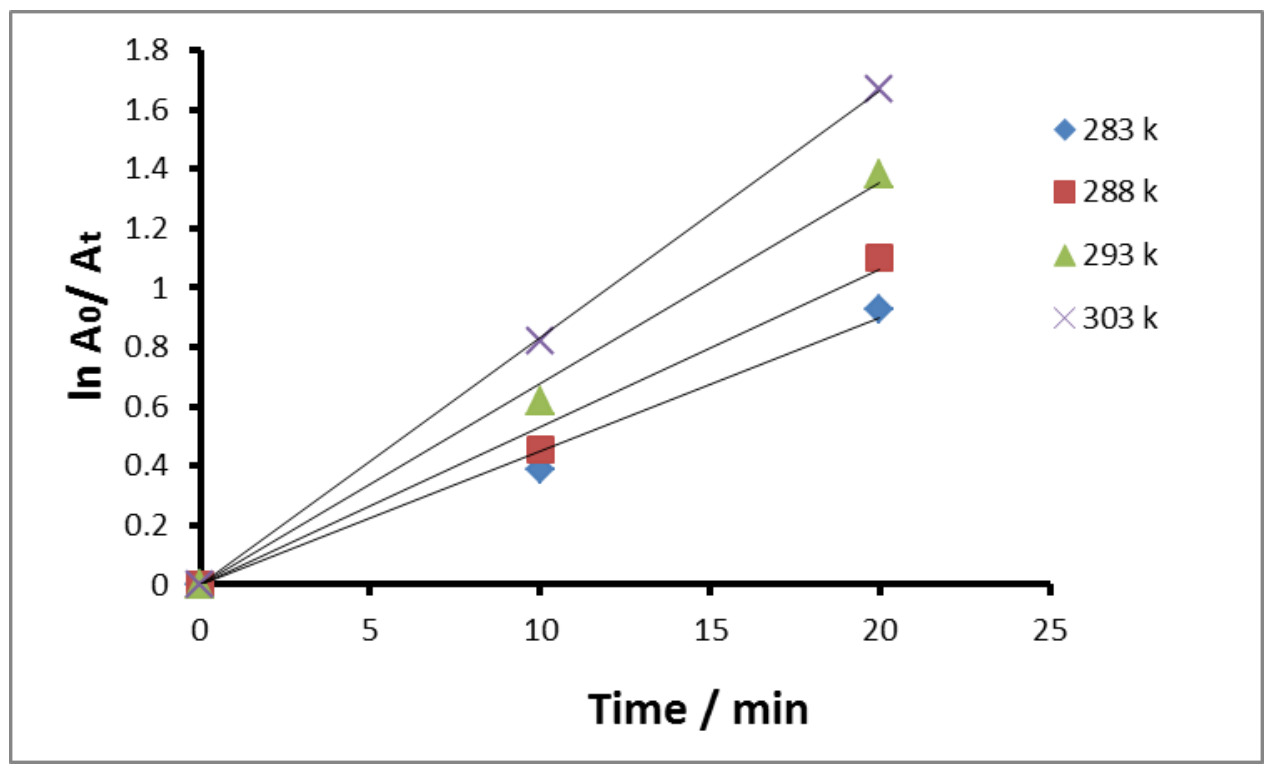

Figure 9 -The change of $\ln \left(\mathrm{A}_{0} / \mathrm{A}_{\mathrm{t}}\right)$ with irradiation time at different temperature using UV radiation, initial orange $\mathrm{G}$ dye concentrations $=15 \mathrm{ppm}$, amount of photo catalyst titanium dioxide nanoparticles $=0.14 \mathrm{gm} / 100 \mathrm{~cm}^{3}, \mathrm{PH}=6.4$. 


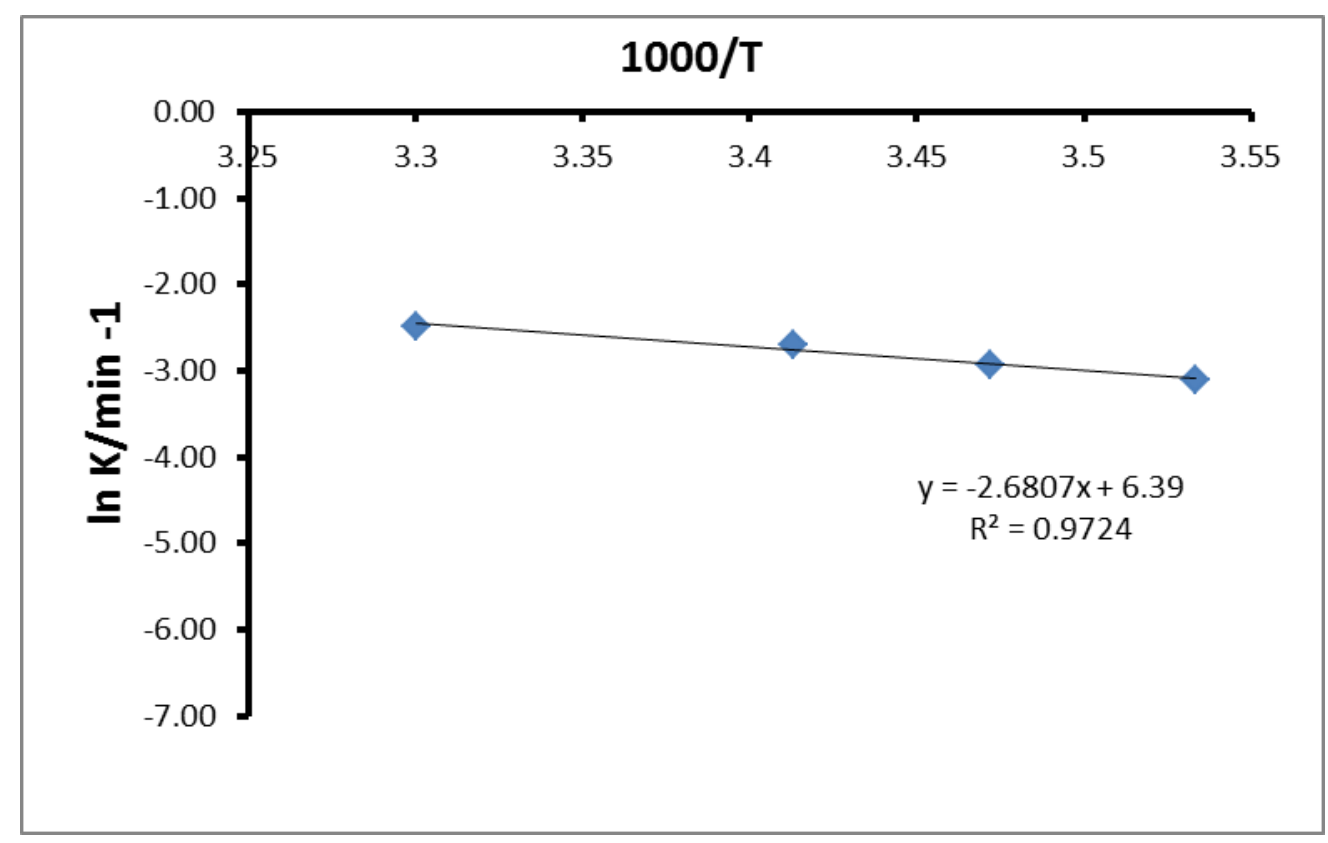

Figure 10 - The change of $\ln \mathrm{K}$ against 1000/T under UV irradiation, initial orange $\mathrm{G}$ dye concentrations $=15 \mathrm{ppm}$, amount of photo catalyst titanium dioxide nanoparticles $=0.14 \mathrm{gm} /$ $100 \mathrm{~cm}^{3}, \mathrm{PH}=6.4$.

\section{CONCLUSION}

The experiment has been carried out in the absence of light (ultraviolet radiation in this work) consequently there is no reaction occur. When the experiment has been performed in the absence of titanium dioxide nanoparticle and the existence of the ultraviolet light, the orange G dye doesn't degradation. The photocatalytic degradation of orange $G$ dye depended on the amount of catalyst loaded and the optimum value equal $0.14 \mathrm{gm} / 100 \mathrm{~cm}^{3}$ of titanium dioxide nanoparticle with15 ppm concentration of orange $\mathrm{G}$ dye as optimum value and light intensity $8.22 \mathrm{~mW} / \mathrm{cm}^{2}$ and 10 $\mathrm{cm}^{3} / \mathrm{min}$ bubble of air . Photocatalytic degradation of orange $\mathrm{G}$ dye follows the first order of reaction .Photocatalytic degradation processes decrease with increase concentration of orange $\mathrm{G}$ dye due to the decrease of the concentration $\mathrm{OH}^{-}$adsorbed on the catalyst surface. The best value of PH of photocatalytic degradation equal 6.4 ,
Photocatalytic degradation process of orange $G$ dye increases with the increase of light intensity because the increase of photoelectron in the conduction band this lead to an increase of a number of electrons-hole pair and, a decrease of recombination process between photoelectron and a hole in valance band. The percentage efficiency of degradation reactive blue equals $\quad 93.98 \%$.The activation energy has been calculated it was found equal to 22.29 $\pm 1 \mathrm{~kJ}^{\mathrm{mol}}{ }^{-1}$.

\section{ACKNOWLEDGMENT}

I sincerely thank for the University of Babylon, College of Science for Women , for providing the necessary infrastructural facilities during my research. 


\section{REFERENCES}

Rosana M. A., Maria C. C., Marcos N. E., Wilson F. J.,(2000). Catalyst deactivation in the gas phase destruction of nitrogen-containing organic compounds using $\mathrm{TiO}_{2} / \mathrm{UV}-\mathrm{VIS}$, Applied Catalysis B: Environmental 793 ,1-9.

MukhlishM.Z., Najnin F., Rahman M.M., Uddin M.J., J. ,(2013),Photocatalytic Degradation of Different Dyes Using $\mathrm{TiO}_{2}$ with High Surface Area: A Kinetic Study ,Sci. Res. 5 (2), 301-314.

Maria V., Luminita A., Anca D.,(2015), Fly ash$\mathrm{TiO}_{2}$ nanocomposite material for multipollutants wastewater Treatment, Journal of Environmental Management, 150 , 336-343.

Maria V., Anca D.,(2013), Methyl-orange and cadmium simultaneous removal using fly ash and photo-Fenton systems, Journal of Hazardous Materials, 244, 773- 779.

Mukhlish M., Najnin F., Rahman M., Uddin M. ,(2013), Photocatalytic Degradation of Different Dyes Using TiO2 with High Surface Area: A Kinetic Study, J. Sci. Res. 5 (2), 301-314.

Fujishima A., Honda K. ,(1972), Electrochemical Photolysis of Water at a Semiconductor Electrode. Nature, 238, 37-38.

Yadollah A., Abdul H. A., Zulkarnain Z., Nor A.Y., (2011), Photodegradation of o-cresol by $\mathrm{ZnO}$ under UV irradiation ,Journal of American Science, 7(8).

Cheng M., Zeng G. , Huang D., Lai C., Xu P., Zhang Ch., Liu Y.,(2016), Hydroxyl radicals based advanced oxidation processes (AOPs) for remediation of soils contaminated with organic compounds: A review, Chemical Engineering Journal, 284: 582-598.

Abouzlam M. , Ouvrard R., Mehdi D.. Pontlevoy F., Gombert B, VelLeitner N. ,
Boukari S. A,(2015), $\mathrm{H}_{\infty}$ control for optimizing the advanced oxidation processes-Case of a catalytic ozonation reactor, Control Engineering Practice, 44,1-9.

Suzuki H., Araki S., Yamamoto H.,(2015), Evaluation of advanced oxidation processes (AOP) using O3, UV, andTiO2for the degradation of phenol in water, Journal of Water Process Engineering, 7:54-60.

Jeirani Z., Sadeghi A., Soltan J. , Roshani B. , Rindall B,(2015), Effectiveness of advanced oxidation processes for the removal of manganese and organic compounds in membrane concentrate, Separation and Purification Technology, 149: 110-115.

Aline M., Sales S., Carlos A. Martínez-H., Sergi G., Abdellatif E., Enric B.,( 2016), Application of electrochemical advanced oxidation processes with a boron-doped diamond anode to degrade acidic solutions of Reactive Blue 15 (Turquoise Blue) dye ,Electrochimica Acta, 197 : 210-220.

Akpan U., Hameed B., (2009), Parameters affecting the photocatalytic degradation of dyes using $\mathrm{TiO}_{2}$-based photocatalysts: A review, Journal of Hazardous Materials, 170 , 520-529.

Yang S.,Lou L.,Wu X., Chen Y., ( 2006), Reaction sit and mechanism in the UV or visible light induced $\mathrm{TiO}_{2}$ photodegradation of orange G, Journal of Environmental Sciences, 18(1),180-183.

Lachhe H., Puzenat E., Houas A., Ksibi M., Elaloui E., Guillard C., Herrmann .M.,(2002), Photocatalytic degradation of various types of dyes (Alizarin S, Crocein Orange G, Methyl Red, Congo Red, Methylene Blue) in water by UV-irradiated titania, Appl. Catal. B: Environ. $39,75-90$. 
Rachita M. and Menka S., ( 2012 ), Comparative study of photo-degradation of dye Acid Orange -8 byFenton reagent and Titanium Oxide- A review , Pharma Chemica, 4 (1):311319 ,

Hazim Y. A. ,(2016), The effect of coupled titanium dioxide and cobalt oxide on photocatalytic degradation of malachite green , International Journal of ChemTech Research, 9(2) : 227-235.

Peidong H., Mingce L.,(2016 ), Cobaltcatalyzed sulfate radical-based advanced oxidation: A review of heterogeneous catalysts and applications, Applied Catalysis B: Environmental, 181, 103-117.

Jianguo S., Zhen X., Wei L., Chang-Tang C.,(2016), $\mathrm{KBrO}_{3}$ and graphene as double and enhanced collaborative catalysts for the photocatalytic degradation of amoxicillin by $\mathrm{UVA} / \mathrm{TiO}_{2}$ nanotube processes, Materials Science in Semiconductor Processing ,52, 3237.

Hazim Y. A., Qasim Y.M.,( 2016 ), Prepared coupled $\mathrm{ZnO}-\mathrm{Co}_{2} \mathrm{O}_{3}$ then study the photocatalytic activities using crystal violet dye, Journal of Chemical and Pharmaceutical Sciences,9(3),1161-1165.

Da-Rui L., Yin -Shan J.,Gui-Mei G.,(2011),photocatalytic degradation of an azo dye using $\mathrm{N}$-doped $\mathrm{NaTaO} 3$ synthesized by onestep hydrothermal process,Chemosphere, $83,1546-1552$

Yadollah A., Abdul H. A., Zulkarnain Z. and Nor A. Y. ,(2012), Photocatalytic Degradation of p-Cresol by Zinc Oxide under UV Irradiation, Int. J. Mol. Sci., 13, 302-315.

Herrmann J.M., Guillard C. and Pichat P., (1993), Heterogeneous photocatalysis: an emerging technology for water treatment

,CatalysTiosd ay, 17,7 -20.,

Evgenidou E., Fytianos K., Poulios I. ,(2005), Photocatalytic oxidation of dimethoate in aqueous solutions, Journal of Photochemistry and Photobiology A: Chemistry, 175 , 29-38.

Wen Y., Young K.,(2006), Photocatalytic degradation of Reactive Red 22 in aqueous solution by UV-LED radiation ,WATER RESEARCH 40, 2249 - 2258.

Hazim Y. A., Eateman S. Almaamory, Hedear H. Alsaady and Ghadeer S. Almurshidy,(2015), Photocatalytic Degradation of Aquatic Rhodamine B Solution Using Ultraviolet Light and Zinc Oxide, Research Journal of Pharmaceutical, Biological and Chemical Sciences, 6, 929.

Hazim Y. A., and Ghadeer S Al Murshidy,(2015), Photocatalytic Decolorization of Brilliant Cresyl Blue using Zinc Oxide, International Journal of PharmTech Research, 8(2), 289-297.

Shaobin W., Boyjoo Y., Choueib A., Zhu Z.H.,(2005), Removal of dyes from aqueous solution using fly ash and red mud, Water Research 39, 129-138.

Ruwaida A, Hazim Y. A., Aseel M.A., Ayad F. A,(2016), Photocatalytic degradation of reactive green dye by using Zinc oxide, Journal of Chemical and Pharmaceutical Sciences,9(3),1134-1138. 